7 Swift G, Nasir M, Sheehan JD, Casey PR. Junior doctors' experience and knowledge of procedures in compulsory psychiatric admissions in Ireland. Ir J Psychol Med 2001; 18: 21-3.

8 Department of Health. Reference Guide to the Mental Health Act 1983. TSO (The Stationery Office), 2008.

9 Department of Health. Code of Practice, Mental Health Act 1983. TSO (The Stationery Office), 2008.

10 Office of Public Sector Information. Mental Health Act 2007 Chapter 12 TSO (The Stationery Office), 2007.

11 Humphreys MS. Persuasion, coercion, medical paternalism or the Mental Health Act: the dilemma of detention in a general hospital. Scot Med J 1992; 37: 146-8.

12 Humphreys MS. Junior psychiatrists and emergency compulsory detention in Scotland. Int J Law Psychiatry 1994; 17: 421-9.

13 Naeem A, Gupta B, Rutherford J, Gachen A, Roberts S. The simulated mental health review tribunal - a valuable training tool for senior house officers? Psychiatr Bull 2007; 31: 29-32.

14 Polit DF, Beck CT. Essentials of Nursing Research (5th edn). Lippincott Williams \& Wilkins, 2006

15 Modernising Medical Careers. A Reference Guide for Postgraduate Specialty Training in the UK (The 'Gold Guide'). MMC, 2009.
16 Munro BH. Statistical Methods for Health Care Research (5th edn). Lippincott Williams \& Wilkins, 2005.

17 Humphreys MS, Kenney-Herbert JP, Cope RV. How to keep up with the Mental Health Act. Adv Psychiatr Treat 2000; 6: 407-11.

18 Lynch RM, Simpson M, Higson M, Grout P. Section 136, The Mental Health Act 1983: levels of knowledge among accident and emergency doctors, senior nurses, and police constables. Emerg Med J 2002; 19: 295-300.

19 Royal College of Psychiatrists. A Competency Based Curriculum for Specialist Training in Psychiatry: Core and General Module. Royal College of Psychiatrists, 2009.

20 Royal College of Psychiatrists. Specialist Training in Psychiatry: A Comprehensive Guide to Training and Assessment in the UK for Trainees and Local Educational Providers (Occasional Paper OP69). Royal College of Psychiatrists, 2010

21 Harrison J. Training in the Mental Health Act: see one, do one, teach one? Psychiatr Bull 1996; 20: 160-1.

22 Peay J, Roberts C, Eastman N. Legal knowledge of mental health professionals: report of national survey. J Ment Health Law 2001; 5: 4455.

23 Affleck GG, Peske MA, Wintrob RM. Psychiatrists' familiarity with legal statutes governing emergency involuntary hospitalisation. Am J Psychiatry 1978; 135: 205-9.

\title{
Mental health law training should be mandatory for all doctors
}

\section{Commentary on ... Knowledge of mental health legislation in junior doctors training in psychiatry ${ }^{\dagger}$}

\section{Christopher Schofield}

The Psychiatrist (2011), 35, 466-468, doi: 10.1192/pb.bp.111.035683

Queens Medical Centre, Nottingham

Correspondence to

Christopher Schofield

(chrisschofield@doctors.org.uk)

First received 16 Jun 2011, final revision

4 Aug 2011, accepted 15 Aug 2011

\begin{abstract}
Summary Over many years and with various pieces of new legislation there are significant gaps in doctors' knowledge about mental health law. It is time to ensure that doctors know the law and can apply it to the patients they see. Practising legally and not detaining or allowing people to leave hospital inappropriately should be a mandatory part of training for every doctor no matter what the specialty. Medical schools, deaneries, training programme directors and the General Medical Council should take up the challenge and ensure good-quality training for all doctors to ensure good-quality care in this area is given to all patients.
\end{abstract}

Declaration of interest None.
The paper by Wadoo et $a l^{1}$ highlights that junior doctors have a lack of knowledge about mental health legislation. It is not the first study to do so and other studies highlight many different areas where knowledge of law is lacking. ${ }^{2-4}$ However, this is an important area to highlight.

Wadoo et $a l^{1}$ state that as theirs is a semi-quantitative study methodologically it is difficult to replicate it.

'See education and training, pp. 460-466, this issue.
However, it shows what other studies before it have shown: that there is a lack of knowledge regarding mental health law - in this case, specific aspects of the Mental Health Act 1983. This lack of knowledge is not necessarily limited to junior trainees and within the study there are hints of this as it shows that in-service training either had no effects on knowledge or in some areas those that received it faired worse in their knowledge.

The phenomenon of senior colleagues not understanding or being up to date with certain parts of the 
Mental Health Act 1983 and the Mental Capacity Act 2005 is seen on many of the teaching courses I have been involved with. It is particularly difficult when senior colleagues have been practising in a certain way for many years, but wordings have changed or case law has altered the way things are now done. When it comes to teaching about Deprivation of Liberty Safeguards (DoLS), things become even more confused as the law is not at all clear in this area.

It is interesting to note that the Royal College of Psychiatrists' exams seem to improve knowledge. This is all the more surprising as the College exams cover a number of different countries each with their own specific mental health legislation. Consequently, the questions in the exam cannot relate specifically to any one piece of legislation as the basis of the legislation can be significantly different. Time in training seems to correlate positively with improved knowledge. It may be that the combination of time in training and the focused study that exams bring about help doctors to learn legislation better.

Mental health legislation is tested for by competencies in regards to applying the law, contrary to what is stated in the paper. The curriculum for core training states that a trainee should be able to 'Apply the legislation appropriately at all times, with reference to published codes of practice ${ }^{5}$ and there are a variety of work-place based assessments that can be used to assess this competency. What may be missing is the application of that competency to the trainee.

\section{Why is the lack of knowledge important?}

Although not proven in this paper, or any other that I am aware of, there is a concern that a lack of knowledge with respects to the law will lead to inappropriate use of mental health legislation on patients. Clearly the most concerning aspect of this is inappropriate detention of people who should not be detained, consequently both depriving someone of their liberty and detrimentally affecting their therapeutic care. There is also the concern that someone is allowed to leave who should be detained and then that individual undertakes risky behaviour to themselves or others.

A secondary problem is compensation. I am aware of some audits that have not yet been published showing that a significant number of detentions are illegal because of forms not having been filled out correctly. Once again these audits cannot prove that lack of knowledge leads directly to these events, but it surely is not too far a leap of logic to suggest that at least there might be a link between them. Each day of illegal detention now has a cost associated with it as does each intramuscular injection given during an illegal detention.

\section{Why might there be this lack of knowledge and what can be done to rectify it?}

As doctors across various specialties have over the years been shown to lack knowledge in mental health legislation it cannot be just down to psychiatric training alone. ${ }^{2-4}$ Medical schools vary tremendously in their depth and breadth of training in the law related to medicine. Some having dedicated time and modules for it, including some having professors of law and ethics applied to medicine, whereas others have little teaching about this area.

Within psychiatry there is another phenomenon with respect to training especially when applied to mental health legislation that requires thoughtful consideration. In discussions with many trainees, very few have had direct supervision of applying a Section 5(2) or doing a Mental Health Act assessment with a senior colleague or see one done before doing one themselves. This direct observation may be difficult to achieve, but with some thought and effort it should not be insurmountable. There is some suggestion that Section 5(2) orders are converted more frequently to a Section 2 or 3 order when discussed with a senior colleague than when not, ${ }^{2,3}$ again suggesting that clinical supervision would better improve care for our patients. Perhaps a minimum number of Assessed Clinical Encounters (ACEs) or mini-ACEs on applying legislation to patients at a certain point of training would focus the minds of trainees and trainers alike.

Improved training in relation to the Mental Health Act 1983 for junior doctors was one of the main recommendations of a well-constructed systematic review done by the Department of Health ${ }^{6}$ conducted more than 11 years ago. Alongside this, teaching has been shown to have positive effects on outcomes of the Mental Health Act. ${ }^{7}$

Surely it is time to consider the importance of this area of training in relation to doctors? With this in mind, practical courses would be very valuable in assisting overall knowledge in this area. One should be aware though that the courses need to be led by trainers with sufficient knowledge, experience and access to up-to-date legal material, otherwise misunderstandings will just be passed on. To that end the courses covering the Mental Health Act, Mental Capacity Act and DoLS run by the Royal College of Psychiatrists (College Education and Training Centre) are put together and overseen by a group of psychiatrists with ongoing input from leading national figures in both psychiatry and law on the content of the courses. This hopefully improves the accuracy of the material and helps keep it relevant and up to date.

Although medical legislation can be found in various competencies including foundation year 1 (F1) competencies, ${ }^{8}$ it is not seen as one of the mandatory competencies and therefore receives less time and recognition. Perhaps practising legally and not detaining or allowing people to leave hospital inappropriately should be a mandatory part of training for every doctor no matter what the specialty.

\section{About the author}

Dr Christopher Schofield (MBBS, MMed Sci, BSc (Hons), MRCPsych) is the College Education and Training Centre (CETC) lead for approved clinician training in the Midlands, a Section 12 trainer for the CETC, the mental health law and ethics module convenor for Masters course at the University of Nottingham and a consultant liaison psychiatrist at Queens Medical Centre, Nottingham. 


\section{References}

1 Wadoo O, Shah AJ, Jehaanandan N, Laing M, Agarwal M, Kinderman P. Knowledge of mental health legislation in junior doctors training in psychiatry. Psychiatrist 2011; 35: 460-6.

2 Buller C, Storer D, Bennett R. A survey of general hospital in-patients detained under Section 5(2) of the 1983 Mental Health Act. Psychiatr Bull 1996; 20: 733-5.

3 Mason P, Turner R. Audit of the use of doctors holding power under Section 5(2) of the Mental Health Act 1983. Health Trends 1994; 26: 44-6.

4 Schofield C. Mental Capacity Act 2005 - what do doctors know? Med Sci Law 2008; 48: 113-6.
5 Royal College of Psychiatrists. A Competency Based Curriculum for Specialist Core Training in Psychiatry: Core Training in Psychiatry CT1-CT3: 36. Royal College of Psychiatrists, 2010.

6 Churchill R, Wall S, Hotopf M, Wessley S. A Systematic Review of Research Relating to the Mental Health Act (1983). Department of Health, 1999.

7 Schofield CJ, Zigmond T. Section 5(2) Mental Health Act 1983: does teaching make a difference? Med Sci Law 2006; 46: 229-32

8 General Medical Council. Tomorrow's Doctors: Outcomes and Standards for Undergraduate Medical Education. GMC, 2009.

\title{
Developing large-group teaching in child and adolescent psychiatry to undergraduate medical students
}

\author{
Aaron K. Vallance, ${ }^{1}$ Victoria Hill, ${ }^{1}$ Cornelius Ani, ${ }^{1}$ Alex Doig, ${ }^{1}$ Elena Garralda ${ }^{1}$
}

The Psychiatrist (2011), 35, 468-472, doi: 10.1192/pb.bp.110.033514

${ }^{1}$ Academic Unit of Child and Adolescent Psychiatry Imperial College London

Correspondence to Aaron Vallance (a.vallance@imperial.ac.uk)

First received 16 Nov 2010, final revision 20 Jul 2011, accepted 15 Aug 2011

\begin{abstract}
Aims and method We developed material for a lecture hall teaching programme in child and adolescent psychiatry for medical students. Although lecture hall settings are not traditionally seen as conducive to exploring concepts, debating positions and encouraging higher-order thinking, we aimed to integrate these processes into the programme alongside educational theory and teaching strategies. We evaluated student and teacher perception of the new material through questionnaires before and after the introduction of the teaching package.

Results Six 1.5-hour teaching sessions were prepared. The evaluation study received 133 student and 4 teacher questionnaires on the previous teaching package, and 99 student and 7 teacher questionnaires on the new material. The questionnaires showed that the redesign resulted in significant improvements in various predefined measures, such as clarity and interactivity of the material.
\end{abstract}

Clinical implications A vivid and memorable teaching programme is essential in shaping students' understanding of the concepts in child and adolescent psychiatry as well as potentially making the specialty more attractive to medical undergraduates.

Declaration of interest None.
The Royal College of Psychiatrists and the General Medical Council (GMC) identify teaching as a key competency and attribute of professional medical training and practice. ${ }^{1}$ Teaching child and adolescent psychiatry to undergraduates, however, poses certain challenges. The specialty calls for clinicians to consider complex biological, psychological and social processes, all in the context of child development. Learning child psychiatry therefore does not just involve memorising facts but also developing certain skills and attitudes, and acquiring a broader understanding through integration of concepts ranging from neuroscience to psychology and social anthropology. A certain amount of teaching and clinical exposure would therefore be required for students to gain a useful understanding of the specialty.

\section{Child psychiatry teaching: current issues}

Medical schools vary significantly in the degree to which the specialty features in the curriculum. ${ }^{2}$ Often lying betwixt and between two departments - psychiatry and paediatrics - child psychiatry can be at risk of being overlooked as the poor relation. Inadequate undergraduate exposure to the specialty may, however, carry repercussions downstream. First, graduates may have a limited appreciation or understanding of child mental health. This is particularly 